\title{
Effects of clear polymer film on emergence and survival of direct sown native vegetation
}

\author{
E. A. Pinkard ${ }^{1 *}$, S. Lisson ${ }^{2}$, T. Bailey ${ }^{3,4}$, N. Davidson ${ }^{4}$, D. Worledge ${ }^{1}$, B. M. Potts ${ }^{3}$ \\ CSIRO Land and Water, Private Bag 12 Hobart 7001 Australia \\ ${ }^{2}$ Consultant to CSIRO, P.O. Box 14, Lauderdale, Tasmania 7020 \\ ${ }^{3}$ School of Biological Sciences and ARC Centre for Forest Value, University of Tasmania, Private Bag \\ 55, Hobart, Tasmania, 7001, Australia. \\ ${ }^{4}$ Greening Australia (Tasmania), 50 Olinda Grove Mount Nelson, 7007 Australia \\ *Corresponding author

\section{Abstract}

Clear, degradable polymer films are used with agricultural crops to alter the germination and growing environment, and extend the length of the growing season. The film acts like a greenhouse, elevating temperatures and improving soil water. We examined the potential of polymer film to improve emergence and persistence of direct-seeded native vegetation. A seed mix comprising three tree species and two shrubs was sown in early August 2015, with and without polymer film. The effect of duration of polymer film (from 0 - 10 weeks) on emergence and persistence was tested, and the effects of polymer film on temperature and soil moisture were monitored. Our hypothesis that polymer film would improve emergence was partially supported, with between 6 and 10 weeks of polymer film coverage increasing emergence of small-seeded species above the level of the Control. The polymer film increased temperatures by an average of $5^{\circ} \mathrm{C}$, and volumetric

This article has been accepted for publication and undergone full peer review but has not been through the copyediting, typesetting, pagination and proofreading process which may lead to differences between this version and the Version of Record. Please cite this article as doi: 10.1002/ldr.2739 
water content by $3 \%$, compared with ambient conditions, and reduced fluctuations in soil moisture, which may have contributed to the increased emergence observed. Emergence was low across all treatments (range0.2-47\%). Our hypothesis that polymer film would improve persistence was not supported, with seedling numbers declining rapidly following removal of the polymer film and no differences between treatments in percentage persistence by the end of the experiment. We concluded that polymer film is a potentially useful tool for improving emergence of smaller-seeded species in direct seeding for land restoration, although provided no benefit for emergence of the larger-seeded species.

Key words: clear polymer film, native vegetation, land restoration, seed emergence, seedling persistence
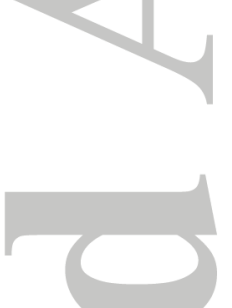

Introduction

Restoration of vegetation on cleared agricultural lands has been a focus of government and private investment globally, as a way of providing a range of potential benefits such as shelter for stock and crops, enhanced biodiversity values, carbon sequestration, and erosion and salinity control (Schirmer \& Field, 1995; Holl et al., 2003; Florentine et al., 2013). The most common approach for revegetating these landscapes is the planting of seedlings (Cole et al., 2011). This is expensive and time-consuming, which limits the area of land that can be revegetated (Ceccon et al., 2016).

Direct seeding is a potentially efficient and economical alternative, or complementary activity, to planting seedlings (Knight et al., 1998). It involves sowing seeds of trees, shrubs and grasses directly into the soil, avoiding the need for propagation and planting. Its major advantage lies in the capacity to establish large areas of vegetation rapidly and relatively cheaply, with costs as much as $50 \%$ lower than seedling establishment (Schirmer \& Field, 1995; Holl et al., 2003). 
There are, however, a number of vulnerabilities associated with direct seeding that mean it is not successful in all situations. A recent meta-analysis of 30 direct seeding experiments covering 89 species found that most attempts at using direct seeding for vegetation restoration were unsuccessful, with no clear links between success and climate, species or pre-germination treatments (Ceccon et al., 2016). Ceccon et al. (2016) did however find that probability of germination and persistence increased with seed size and with the use of physical protection that created a favourable microclimate such as wood veneer or bottomless cups.

Some of the factors contributing to direct seeding failure may include seed foraging, insufficient soil water availability to support germination and survival, unfavourable germination temperatures and low relative humidity (Andersen, 1989; Banerjee et al., 2006; Guarino \& Scariot, 2014). All of these factors are difficult to control in a field situation. Light and moisture competition from weeds also can be contributing factors (Baker et al., 1988; Knight et al., 1998).

Clear, degradable polymer films (hereafter referred to as polymer film) alter the germination and growing environment and have the potential to allow earlier sowing and greater certainty around the time of sowing in areas that are otherwise limited by the timing of rainfall events, available soil water and low temperatures (Lisson et al., 2015). Polymer films are made from a thin (200 - 2500 $\mathrm{nm}$ ) layer of impervious and stretchable petroleum-based polyolefin or bio-derived materials. Strips of this material are installed over a newly sown crop and the edges buried on either side with soil. The polymer film acts as a greenhouse, trapping radiant heat and elevating temperatures (Miller \& Bunger, 1963); trapping soil and plant transpiration thereby improving soil water potential and increasing relative humidity (Lisson et al., 2015); and increasing atmospheric $\mathrm{CO}_{2}$ concentrations (Lisson et al., 2015) (Figure 1). The higher temperatures and potentially faster establishment rates can be used to grow crops outside their typical environmental thresholds (Lisson et al., 2015), and polymer film is currently used around the world to promote faster and higher rates of establishment, increased production and earlier maturation of both broad scale and intensively-managed crop 
species such as corn (Orzalek et al., 2000), wheat (Li et al., 1999), potatoes (Lamont et al., 2005) and strawberries (Singh et al., 2007). However polymer film can also expose germinants and young plants to supra-optimal temperatures capable of causing mortality during spring and summer, associated with increasing day length and solar energy intensity (Miller \& Bunger, 1963). Exposure to supra-optimal temperatures can be avoided by removing polymer film during spring before conditions become too warm, but at sites where ambient climatic conditions are less favourable, there is risk of plants experiencing cold shock that can limit survival and growth (Sanchez et al., 2014).

While the germination and survival of target species for direct seeding may be improved under polymer film, weed species also flourish, and weed competition is considered to be a major disadvantage of using polymer film with direct seeding. Once the film is in place, follow-up weed control is very difficult.

Despite these potential drawbacks, polymer film offers a tool for direct seeding for vegetation restoration, as a means of managing temperatures and the soil moisture environment to improve direct seeding outcomes, and potentially limiting vertebrate and invertebrate seed foraging. However, there is virtually no published research examining the potential for using polymer film to improve the outcomes of native vegetation establishment. We conducted a field experiment to test the hypothesis that polymer film would improve emergence and persistence in direct-seeded native vegetation on cleared agricultural land. This study addresses the following questions: (1) to what degree were emergence and persistence promoted by polymer film? (2) how long did polymer film need to be in place to give optimal results? (3) what characteristics of the environment under polymer film may have contributed to results?

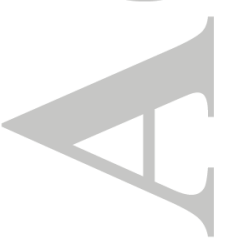




\section{Methods}

Site

The experiment was established in the Northern Midlands of Tasmania, Australia, on a site previously used for livestock grazing and cereal production ( $41^{\circ} 45^{\prime} 27.73^{\prime \prime} \mathrm{S} 147^{\circ} 09^{\prime} 39.01^{\prime \prime} \mathrm{E}, 154 \mathrm{~m}$

a.s.I.). Mean annual rainfall at the closest Bureau of Meteorology monitoring site, Cressy, is $600 \mathrm{~mm}$ from 137 rain days spread evenly over the year. Mean annual maximum and minimum temperatures are 18.1 and $5.6^{\circ} \mathrm{C}$, respectively, in January and July (BOM.gov.au, accessed on 17/8/2016)

The site is gently sloping to the south, with a deep chromosol soil (Davies, 1988). In early July, grasses and herbaceous weeds were removed using glyphosate, a contact herbicide applied in 50 $\mathrm{cm}$-wide strips using a boom spray applicator at a rate of $2 \mathrm{l} / \mathrm{ha}$. Clopyralid, a translocated herbicide that is selective to plants of the Asteraceae and Leguminaceae, was applied at $150 \mathrm{~mL} / \mathrm{ha}$ to control the broadleaf species Arctotheca calendula (cape weed). The site was fenced to exclude stock although it was still subject to some disturbance by native marsupials and feral deer late in the experiment.

\section{(n) \\ Species and experimental design}

The experimental design consisted of four blocks of $50 \mathrm{~m}$ length, oriented down the slope, containing four replicates of each treatment within each block. This design gave a total of 16 replicates per treatment. Details of the design are given in Figure 2. The treatments were as follows:

1. Absolute control: row scalped using a Burford direct seeder (details below) but no seed sown

2. Control: seed sown but no polymer film applied (Control)

3. Seed sown and polymer film applied; polymer film removed immediately (PO) 
4. Seed sown and polymer film applied: polymer film removed after 2 weeks (P2)

5. Seed sown and polymer film applied: polymer film removed after 6 weeks (P6)

6. Seed sown and polymer film applied: polymer film removed after 10 weeks (P10)

7. Seed sown and polymer film applied+ chicken wire cage: polymer film removed after 10 weeks (P10+cage)

Treatment 1 was included to account for any natural colonisation from the 6 mature eucalypt trees within the experimental area, or from soil-stored seed. Treatment 3 allowed us to test for any effects specifically associated with polymer film application process. Treatment 7 was included to prevent damage to the polymer film from animals or birds. The cages comprised $2.5 \mathrm{~cm}$ gauge bird mesh that was placed loosely over the polymer film and pegged to the ground. The mesh was removed when the polymer film was removed, and then immediately replaced to restrict animal damage. Linear plots of $10 \mathrm{~m}$ length and the width of a sowing line (approx. $30 \mathrm{~cm}$ ) were established for each treatment replicate, with an internal measurement plot of $8 \mathrm{~m}$. For ease of application of polymer film, the plots with polymer film treatments were contiguous. Treatments 3 to 7 were randomly positioned within a $50 \mathrm{~m}$ sowing line, but the control plots (Treatment 1 and 2 ) were placed on the adjacent sowing line to which polymer film was not applied (Figure 2).

The seed mix comprised Eucalyptus ovata, Acacia dealbata, Allocasuarina verticillata, Cassinia aculeata and Hakea macrocarpa (Wildseed Tasmania Pty Ltd). Close to the time of sowing, the $A$. dealbata seed was heat treated by covering with boiling water and soaking for 12 hours (Greening Australia 1996). The treated seeds were air-dried. All seed was stored at room temperature until sown. Seed of the other species did not require pre-treatment (Neil Davidson, Greening Australia, pers. comm.).

Seeding rates are given in Table 1 . The rates were determined from seed viability information provided by the seed supplier. Seed was sown in lines using a Burford direct seeder with a polymer film layer attached, in late July 2015. The soil at the time of sowing was moist following recent rain. 
The Burford direct seeder scalps approximately $5 \mathrm{~cm}$ deep $\times 30 \mathrm{~cm}$ wide from the soil surface, and produces a shallow groove into which seed is sown. It has two seed boxes: one for large seed which delivers seeds into a slit in the soil, and one for small seed that delivers seed to the scalped surface. A pneumatic wheel is used to press the seed into the soil. The seed is sown with no bulking agent. The seed is delivered using sponge rollers that remove the seed from the seed boxes at a predetermined rate. That rate was adjusted prior to seeding, and the sowing rates per species are given in Table 1 as verified through the calibration process. UV stabilised, clear polyethylene propagation film of $10 \mu \mathrm{m}$ thickness and $1.2 \mathrm{~m}$ width (http://integratedpackaging.com.au) was applied at the same time as sowing, in a single pass operation. A middle section of approximately $30 \mathrm{~cm}$ of the polymer film was left clear, with the polymer film buried on each side by the seeder. The Burford seeder achieves this burial using the soil material removed during the scalping process. Where burial by the Burford seeder was inadequate, it was supplemented by manual burying to ensure the polymer film was tightly applied and well-anchored.

Plots were monitored for the number of seedlings of each species present 2, 6, 10, 14, 18 and 28 weeks after sowing. Data were analysed using repeated measures analysis of variance, with treatment and treatment by time interaction as a fixed effects, replicate as a random effect and time as the repeated factor. Percentage emergence per species was calculated as the maximum number of plants per plot divided by the estimated number of seeds sown per plot. Persistence was calculated as the final number of seedlings/maximum number emergents per species. Analysis of variance was used to examine differences between treatments. Standard errors were calculated using least significant differences. All statistical analyses were performed using Genstat 10 (VSN International, UK).

Seedling growth was not monitored because animal browsing was observed in many plots towards the end of the experiment. The fencing was insufficient to control access of feral deer to the site (Bailey et al., 2015), and most browsing was attributed to this species. 


\section{Environmental conditions}

A weather station was established on the western boundary of the experiment. The station logged maximum and minimum air temperatures and relative humidity on a 30 minute time-step using Tinytag sensors. Daily rainfall was measured using a tipping bucket rainfall gauge with a Tinytag data logger.

Physical soil conditions under and external to the polymer film were monitored from July until the end of September when all polymer film had been removed, using HOBO 12-bit temperature (model S-TMB-M006) and soil moisture (model S-SMx-M005) sensors, that logged at 15 minute intervals. Three temperature probes, that averaged across their $5 \mathrm{~cm}$ length, were placed either under or adjacent to the polymer film at the soil surface, in one randomly selected P10 plot. In the same plot, two soil moisture sensors, that averaged along their $7.5 \mathrm{~cm}$ length, were placed both under and adjacent to the polymer film. The location of all sensors was randomly selected.

The weed cover (\%) per plot was estimated subjectively as $N=$ no weeds; $L=$ weeds $<20 \%$ of total soil surface; $\mathrm{M}=$ weeds $21-50 \% ; \mathrm{H}=$ weeds $>50 \%$. Weed cover was monitored at each measurement time.<smiles>C1CCC1</smiles>

Integrity of the polymer film

The polymer film was manufactured to break down after around 10 weeks of exposure to UV radiation. At each measurement time, the integrity of the polymer film was scored subjectively as the $\%$ holes over the total surface.

This article is protected by copyright. All rights reserved. 


\section{Results}

Ambient climatic conditions during the experiment

Mean air temperatures measured at $1.3 \mathrm{~m}$ height ranged from a minimum of $-2.2^{\circ} \mathrm{C}$ in August, up to a maximum of 35.4 in January (Figure 3A). During the period of polymer film coverage, surface soil temperatures were more moderate than the maximum and minimum temperatures measured at 1.3 $\mathrm{m}$, ranging from $1.4-21.1^{\circ} \mathrm{C}$ (no polymer film) and $2.7-27.4^{\circ} \mathrm{C}$ (with polymer film). Mean monthly rainfall over the period of the experiment averaged $34 \mathrm{~mm}$, but was highly variable with only 1.4 $\mathrm{mm}$ in October and $113 \mathrm{~mm}$ in January (Figure 3B).

Effect of polymer film on the physical environment

Surface soil temperatures recorded under the polymer film never reached higher than $28^{\circ} \mathrm{C}$ (Figure 3C), although were trending upwards, similar to previous studies in Tasmania that found air temperatures in the headspace under polymer film start to become very high from early October through to March (Lisson et al., 2015). Both maximum and minimum soil temperatures were elevated under polymer film by an average of $5^{\circ} \mathrm{C}$ (Figure 3C, E), but are unlikely to have become too high for germination or plant function (e.g. Boland et al., 1980; Battaglia, 1993).

While soil water content declined over the period following sowing, the decline was slower and more uniform under the polymer film than in ambient conditions (Figure 3D). When the polymer film was removed in September, the soil moisture content was $37 \%$ higher under polymer film than in the open (Figure 3D, F). For most of the period that polymer film was present, it resulted in a higher volumetric soil water content than was observed without polymer film (Figure 3F). Following removal of the polymer film, differences between the treatments in soil water content disappeared within five days (data not shown). 
Integrity of polymer film

The polymer film generally retained its integrity up to and including 6 weeks after sowing. Four plots in the P6 treatment were excluded from measurement due to animal damage to the polymer film. By the 10 week assessment, there was further evidence of damage from animals particularly deer (mean damage $18 \%$ of surface area; range $5-70 \%$ ); in P10+CAGE, damage to the polymer film was minimal (mean 1\%; range $0-5 \%$ ) and probably related to the 10 week 'shelf life' of the particular polymer film used in the experiment. This is evidence that the majority of damage to the polymer film was animal-derived.

Weed cover

Approximately $72 \%$ of plots remained weed-free for the duration of the experiment. A further $15 \%$ had low $(<20 \%)$ weed cover. Analysis showed that weed cover\% did not significantly affect seedling emergence (data not shown).

Seedling emergence and persistence

There was no emergence observed in Treatment 1 . We concluded that there was unlikely to have been emergence related to either soil-stored seed or seedfall from mature trees within the plots.

Rates of emergence were very low compared to the nominal number of viable seeds per plot (Table 1), irrespective of treatment. The maximum emergence was $47 \%$ for $A$. dealbata, $7.8 \%$ for $E$. ovata, $6.8 \%$ for $H$. microcarpa, $4.3 \%$ for $A$. verticillata, and $1.0 \%$ for $C$. aculeata.

There was a strong time $\mathrm{x}$ treatment interaction for each species $(\mathrm{P}<0.0001)$, as illustrated in Figure 4. For example, for $A$. dealbata, a large-seeded species, no emergence was observed until the 10 week monitoring (Figure 4A). While the P10 and P10+CAGE treatments increased emergence at 10 
weeks by 400 and $480 \%$ respectively compared with the Control, by week 14 emergence from the Control and P0 treatments was double that promoted by polymer film.

Allocasuarina verticillata emergence was first observed at week 6 , and the P6 treatment resulted in 2.5 emergents per plot compared with 0.4 per plot in the Control (Figure 4B). However peak emergence of this species was observed in the Control and P0 treatments (Table 2).

Emergence of $C$. aculeata was substantially promoted by the P10+CAGE treatment (Figure 4C), and this advantage was retained for the duration of the experiment. Shorter term polymer film coverage provided a small increase in emergence, but numbers declined rapidly following removal of the polymer film.

Eucalyptus ovata emergence was first observed within 6 weeks of sowing (Figure 4D), and the number of plants emerging gradually increased to a peak at weeks 17 and 14 in the Control and PO treatments, respectively. The presence of polymer film increased emergence in the P10 treatment by $23 \%$, and in the P $10+$ CAGE treatment by $21 \%$, but seedling numbers declined rapidly following polymer film removal. Shorter-term polymer film application (P2, P6) resulted in a decline in percentage emergence compared with the control (Table 2).

Very little emergence of $H$. microcarpa was observed in treatments other than P10 and P10+CAGE both of which significantly increased emergence (Figure 4E). As with E. ovata, the number of emergents declined rapidly following removal of the polymer film, and by the end of the experiment very few of this species remained (Table 2).

Percentage emergence (Table 2) (maximum number of plants/number of seed sown) of $A$. dealbata and $A$. verticillata was significantly reduced by the presence of polymer film, but was increased by 6 weeks of polymer film cover for $C$. aculeata $(P<0.001)$. Ten weeks of polymer film coverage increased percentage emergence of E. ovata and H. microcarpa, both with and without a cage. With the addition of a cage, emergence of $C$. aculeata also increased. 
Persistence of emergents varied between species $(P<0.001)$, averaging $80 \%$ for $A$. dealbata, down to $4 \%$ for $H$. microcarpa (Table 2). Polymer film had no significant effect on persistence within species $P>0.05)$.

\section{Discussion}

Were emergence and persistence promoted by polymer film?

Our hypothesis that polymer film would improve emergence of direct-seeded native vegetation was partially supported. Ten weeks of polymer film coverage increased emergence of $E$. ovata, $C$. aculeata and H. microcarpa, above levels measured in the control. However, of the large seeded species, A. dealbata and A. verticillata, maximum emergence was recorded in the Control and P0 treatments, despite the initial boost in emergence under polymer film. Polymer film therefore afforded no advantage for these species at this site, and our results suggested that shorter periods of polymer film coverage reduced percentage emergence. Instead, it was in the smaller-seeded species, C. acuminata, E. ovata and H. microcarpa, where emergence benefitted most from the presence of polymer film.

The low rates of emergence irrespective of treatment (range $0-47 \%$, mean $3.6 \%$ ) are similar to results reported in other direct seeding trials (Ray and Brown, 1995; Madsen and Löff, 2005; Ceccon et al., 2016), and may reflect seed foraging. For example, seed predation of 12 native tree species in Brazil accounted for up to $77 \%$ removal of seed in direct seeding experiments in abandoned pastures (Guarino \& Scariot, 2014), and vertebrate exclusion treatments increased emergence of some eucalypt species by up to 15 -fold (Stoneman, 1993). An experiment performed on the same site found that treating seed with insecticide dramatically increased emergence compared to a control treatment (T. Bailey, unpublished data), suggesting that foraging may have been partially 
responsible for the poor emergence. It seems that polymer film did not exclude seed foraging, and that other methods of reducing foraging may need to be applied in conjunction with polymer film.

Our hypothesis that polymer film would promote persistence was not supported. The hypothesis assumed that plants under polymer film would grow faster than those in the open, meaning plants would have larger root systems for water harvesting and higher leaf area for photosynthesis, providing them with an advantage once the polymer film was removed, as has been found in crop species (Orzalek et al., 2000). However, there was no effect of polymer film on percentage persistence over the duration of the experiment, and in the four weeks following polymer film removal, seedling numbers declined in $H$. microcarpa, E.ovata and $A$. verticillata. It is possible that the removal of the polymer film, and the resultant abrupt change in microclimate, were responsible for seedling mortality. Rainfall in particular was very low in the month following polymer film removal in the P10 treatment. This type of 'shock' has been documented in crop species (Sanchez et al., 2014). For operational direct seeding, the gradual breakdown of degradable polymer film, rather than the abrupt removal of polymer film used in our experiment, may help to overcome this problem. Alternatively, perforating the polymer film sometime prior to removal may increase seedling persistence following polymer film removal by allowing plants to acclimate slowly to ambient environmental conditions. This may be impractical for large scale direct seeding. Perforated polymer film products are being developed and tested for use with crop species, and also may help overcome problems associated with an abrupt change in microclimate (S. Lisson, pers. comm.).

An alternative explanation for the poor persistence following polymer film removal may be preferential browsing of plants in the polymer film treatments. Despite our best efforts, it was impossible to keep feral deer out of the site in spring and summer. This species is protected in Tasmania and control measures are limited to fencing, which was only partially successful at our site. Seedling growth was not monitored at the site because of evidence of deer browsing in the non- 
polymer film treatments around 10 weeks into the experiment. It is possible that attributes of some of the species growing under polymer film made them more attractive to browsing animals in the period following polymer film removal, for example more tender foliage and shoots. The absence of weeds may have contributed to browsing of direct-sown species by reducing choice for browsing animals.

What duration of polymer film presence gave optimal results?

Success of direct seeding is partly dependent on timing the sowing to coincide with high soil moisture conditions. In our study there was little rain until July, so the sowing occurred in early August. Highest emergence from under polymer film was observed in the P10 treatments, with or without caging. The maximum duration of polymer film covering was determined by (1) the sowing date, and (2) the date at which high temperatures under polymer film would start to limit survival. It has been demonstrated that having polymer film in place later than the end of October risks critically high temperatures in this region (Lisson et al., 2015). It is unclear whether, if sowing had been earlier (e.g. late autumn or early winter), there would have been additional benefits to emergence and persistence from a longer duration of polymer film coverage. Polymer film is used in crop species to enable earlier sowing and to extend the growing season (Li et al., 1999; Orzalek et al., 2000; Lamont et al., 2005). Larger plants should be better equipped to withstand summer growing conditions, with bigger root systems to harvest water and greater leaf area for capturing carbon for growth. However, further research is required to determine whether longer periods of polymer film coverage, or earlier sowing and polymer film deployment, may provide additional advantages for native vegetation establishment.

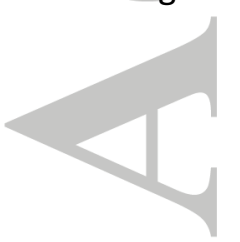


What characteristics of the polymer film headspace may have contributed to results?

The polymer film increased soil temperatures in August to those experienced without polymer film in September. This, combined with the consistently higher soil water content under polymer film in September, may explain the higher percentage emergence observed for many species in the P10 treatments than the Control. Temperatures were on average $5{ }^{\circ} \mathrm{C}$ warmer, and volumetric soil water content was around $3 \%$ greater, under polymer film.

All plants have a range of temperatures at which seed germination can occur, although for many species targeted by direct seeding, germination requirements are poorly understood and restricted to optimal temperatures rather than low and high critical temperatures. The optimal germination temperatures for many of the species included in this experiment are not known. However, for 415 eucalypt species, optimal temperatures varied between $15-35{ }^{\circ} \mathrm{C}$ in laboratory tests (Boland et al., 1980). Temperatures in this range were not reached until late August in our experiment. The optimal germination temperature for $A$. dealbata is around $25^{\circ} \mathrm{C}$ under controlled conditions (http://www.treeproject.org.au/seedling-database/acacia-dealbata, accessed 16/8/2016). This may explain the lack of emergence of this species during August.

The more consistent, and higher, soil water content under polymer film may have helped seed to maintain critical water contents for germination (Boland et al., 1980; Gibson \& Bachelard, 1987). Water strongly influences germination and is one of the key climatic variables influencing the success of direct seeding. Germination rate declines rapidly as soil matric potential becomes more negative, although this is commonly a threshold response rather than linear. For example, in four dryland eucalypt species, all germination ceased when soil water potential reached $-1 \mathrm{MPa}$, with a rapid decline occurring between -0.5 and $-1 \mathrm{MPa}$ (Schutz et al., 2002). In the cool temperate eucalypt species Eucalyptus delegatensis, no germination occurred at -1 $\mathrm{MPa}$, with a rapid drop-off in germination rate when soil matric potential was greater than -0.1 MPa (Battaglia, 1993). However there is evidence that high relative humidity can result in high rates of germination even when soil 
water potentials are low (Bachelard, 1985; Gibson \& Bachelard, 1987). Although we did not measure relative humidity in this experiment, high humidity compared to ambient is commonly reported under polymer film (Lisson et al., 2015).

Carr et al. (2007) found that different species germinated better in different seasons, with Acacia species germinating better when sown in Autumn, and Eucalyptus species performing better following a Spring sowing. They suggested that suites of species with similar germination requirements should be grouped for sowing in different seasons. Polymer film may reduce the need for such an approach by providing more uniform germination conditions over an extended period of time.

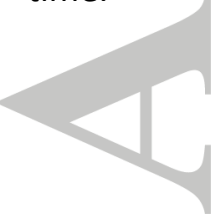

Implications for land restoration

From a land restoration perspective, direct seeding at this site was successful. By the end of the experiment, the number of seedlings per $8 \mathrm{~m}$ measurement plot averaged between 9 (P2) and 17 (Control), although these numbers may decline further into the future. However, between 50 and $80 \%$ of these plants were acacias, for which polymer film offered no advantage. Where a broader mix of species is desirable, polymer film can help promote emergence, particularly of smaller-seeded species. Further research is required to develop methods for improving persistence following polymer film removal, including methods of promoting acclimation to ambient conditions prior to polymer film removal; examining whether using polymer film in conjunction with earlier (Autumn/early Winter) direct seeding can enhance growth; determining whether larger plants at the start of summer will have greater persistence; and identifying physiological and morphological characteristics of plants grown under polymer film that may influence persistence.

\footnotetext{
A clear area of concern is the low emergence rates recorded in this and other direct seeding experiments (Ray and Brown, 1995; Ceccon et al., 2016). Seed purchase comprises a significant
} 
component of direct seeding costs. Improving our understanding for the reasons for low emergence rates is critical to reducing direct seeding costs. Other studies point to seed foraging as a major cause of low emergence following direct seeding (Andersen, 1989; Florentine et al., 2013; Guarino \& Scariot, 2014). Better understanding critical temperature and moisture thresholds for target species will also help explain low emergence rates.

Polymer film offers an additional tool for improving direct seeding outcomes. Other techniques are being developed for use with direct seeding, including liquid film mulching that has been shown to result in high germination rates and fast early growth of rapeseed (Dang et al., 2016). Future experiments could include such methods as well as polymer film for improving emergence and persistence in land restoration projects.

\section{Conclusions}

Our research has shown that using polymer film in conjunction with direct seeding is a potentially useful tool for land restoration, as it can aid emergence of some species, although it is unclear whether it is an economically viable option. What is now required is development of a larger network of polymer film experiments incorporating different site and environmental conditions, and aimed at improving seed emergence and seedling persistence. A major constraint arises, however, for optimising polymer film management for seed mixes of species that react differently to the conditions created by the polymer and its removal.

\section{Acknowledgements}

We thank Integrated Packaging for providing the polymer film and access to the Burford direct seeder, and Greening Australia (South Australia) for assistance in operating the seeder. The project was part-funded by the Cooperative Research Centre for Polymers. BMP also acknowledges support 
from the ARC Linkage grant scheme (LP120200380), held in partnership with Greening Australia,

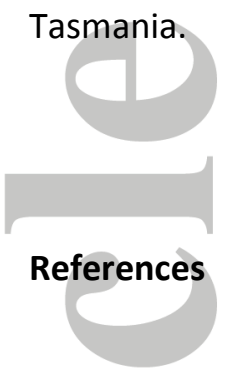

Bachelard EP. 1985. Effects of soil mositure stress on the growth of seedlings of three eucalypt species. I. Seed germination. Australian Forest Research 15:103 - 114

Bailey TG, Gauli A, Tilyard P, Davidson NJ, and Potts BM. 2015. Feral deer damage in Tasmanian biodiverse restoration plantings. Australasian Plant Conservation. 23:10- 12.

Baker TG, Cameron JN, Fagg PC, and Matthews D. 1988. Effect of timing and rate of hexaxinone application on weed control and early growth of Pinus radiata on two contrasting sites. Australian Forestry 51:92 - 97. DOI:10.1080/00049158.1988.1067.4520

Banerjee MJ, Gerhart VJ, and Glenn EP. 2006. Native plant regeneration on abandoned desert farmland: effects of irrigation, soil preparation and amendments on seedling establishment. Restoration Ecology 14:339 - 348. DOI: 10.1111/j.1526-100X.2006.00142.x

Battaglia M. 1993. Seed-germination physiology of Eucalyptus delegatenis Baker,R.T. in Tasmania. Australian Journal of Botany 41:119-136. DOI: 10.1071/BT9930119

Boland DJ, Brooker MIH, Turnbull JW, and Kleinig DA. 1980. Eucalyptus seed. CSIRO, Canberra, Australia

Carr D, Bonney N, and Millsom D. 2007. The effect of sowing season on reliability of direct seeding. Rural Industries Research and Development Corporation Publication No. 07/105, Canberra, Australia

Ceccon E, Gonzalez EJ, and Martorell C. 2016. Is direct seeding a biologically viable strategy for restoring forest ecosystems? Evidence from a meta-analysis. Land Degradation and Development 27:511 - 520. DOI: 10.1002/Idr.2421

Cole RJ, Holl KD, Keene CL, and Zahawi RA. 2011. Direct seeding of late-successional trees to restore tropical montane forest. Forest Ecology and Management 261:1590 - 1597. DOI: 10.1016/j.foreco.2010.06.038

Davies J. 1988. Land Systems of Tasmania. Region 6: South, east and midlands - a resource classification survey. Department of Agriculture, Hobart, Australia, 100 p.

Florentine SK, Graz FP, Ambrose G, and O'Brien L. 2013. The current status of different age, directseeded revegetation sites in an agricultural landscape in the Burumbeet region, Victoria, Australia. Land Degradation and Development 24:81 - 89. DOI: 10.1002/Idr.1110 
Gibson A, and Bachelard EP. 1987. Provenance variation in germination response to water stress of seeds of some eucalypt species. Australian Forest Research 17:49 - 58

Greening Australia. 1996. Seed germination dataset. 1. The acacias. http://www.florabank.org.au/files/documents/seedgerminationanddo/20070801-16.pdf

Guarino, E.D.G. and A. Scariot. 2014. Direct seeding of dry forest tree species in abandoned pastures: effects of grass canopy and seed burial on germination. Ecological Restoration. 29:473 - 482.

DOI: $10.1007 / \mathrm{s} 11284-014-1143-4$

Holl KD, Crone EE, and Schultz CB. 2003. Landscape restoration:moving from generalities to methodologies. Bioscience 53:491 - 502. DOI: 10.1641/00063568(2003)053[0491:LRMFGT]2.0.CO;2

Knight AJP, Beale PE, and Dalton GS. 1998. Direct seeding of native trees and shrubs in low rainfall areas and on non-wetting sands in South Australia. Agroforestry Systems 39:225 - 239. DOI: 10.1023/A:1005901111273

Lamont WJ, Orzalek MD, Otjen L, and Simpson T. 2005. Production of potatoes using plasticulture. Proceedings of American Society of Plasticulture. 33rd National Conference, November 3-4., San Antonio, USA, 2005

Li FM, Guo AH, and Wei H. 1999. Effects of clear plastic film mulch on yield of spring wheat. Field Crops Research 63:79 - 86. DOI: 10.1016/S0378-4290(99)00027-1

Lisson SN, Tarbarth M, Corkrey R, Pinkard E, Laycock B, Howden SM, Botwright Acuna T, and Makin A. 2015. Ambient climate and soil effects on the headspace under clear mulch film. DOI: 10.1016/j.agsy.2015.11.004Agricultureal Systems 142:41 - 50

Madsen P and Löff M. 2005. Reforestation in southern Scandanavia using direct seeding of oak (Quercus robur L.). Forestry 78:55 - 64. DOI: 10.1093/forestry/cpi005

Miller DE, and Bunger WC. 1963. Use of plastic soil covers in sweet corn production. Agronomy Journal 55:417 - 419

Orzalek MD, Lamont WJ, and Cowell G. 2000. Early sweet corn production using the Xtend system. Proceedings International and National Agricultural Plastics Congress 29:568 - 574

Ray G and Brown BJ. 1995. Restoring Caribbean dry forests: evaluation of tree propagation techniques. Restoration Ecology 3:86 - 94.

Sanchez B, Rasmussen A, and Porter JR. 2014. Temperatures and the growth and development of maize and rice: a review. Global Change Biology 20:408 - 417. DOI: 10.1111/gcb.12389

Schirmer J, and Field J. 199) The cost of revegetation. Department of Environment, Canberra Schutz W, Milberg P, and Lamont BB. 2002. Germination requirements and seedling response to water availability and soil type in four eucalypt species. Acta Oecologica 23:23 - 30. DOI: 10.1016/S1146-609X(01)01130-4

This article is protected by copyright. All rights reserved. 
Singh R, Sharma RR, and Goyal RK. 2007. Interactive effects of planting time and mulching on 'Chandler' strawberry (Fragariaxananassa Duch.). Scientia Horticulturae 111:344 - 351. DOI: 10.1016/j.scienta.2006.11.002

Stoneman GL. 1993. Ecology and physiology of establishment of eucalypt seedlings from seed: A review. Australian Forestry 57:11-30. DOI: 10. 1080/00049158/1994.10676109

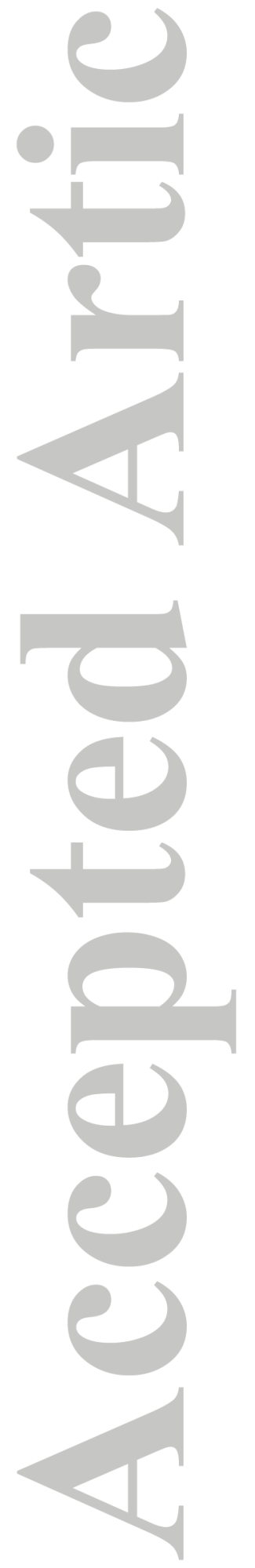


Table 1. Sowing rates for the Connorville direct seeding experiment, in $\mathrm{g} / \mathrm{km}$ and number of seeds per $8 \mathrm{~m}$ plot.

\begin{tabular}{|l|c|c|}
\hline \multirow{2}{*}{ Species } & \multicolumn{2}{|c|}{ Sowing rate } \\
\cline { 2 - 3 } & $\mathbf{g} / \mathbf{k m}$ & No seeds \\
\hline & & sown/plot \\
\hline Eucalyptus ovata & 17 & 61 \\
\hline Acacia dealbata & 60 & 128 \\
\hline Allocasuarina verticillata & 40 & 640 \\
\hline Cassinia aculeata & 16 & 72 \\
\hline Hakea microcarpa & 30 & \\
\hline
\end{tabular}

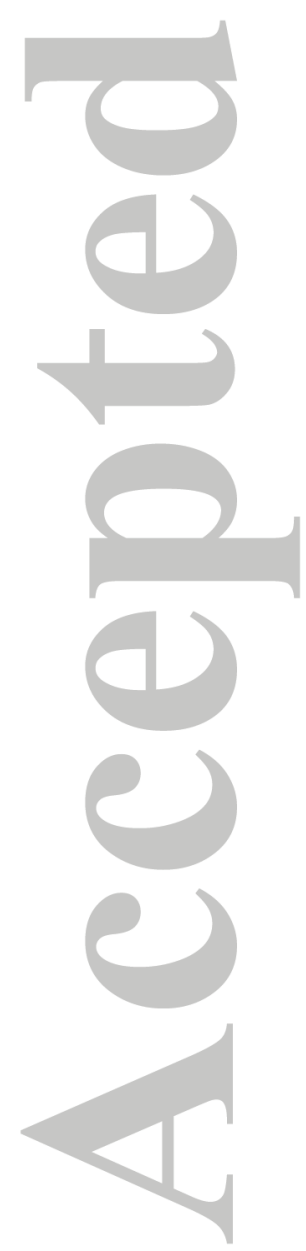

This article is protected by copyright. All rights reserved. 
Table 2. Percentage emergence of five species observed at the Connorville site, expressed as the maximum number of plants/number of seeds sown $\times 100$. Persistence was calculated as final number of plants per species, divided by the maximum emergence per species. *indicates significant differences between treatments within species $(P<0.05)$. the Control indicates no polymer film treatment; P0, P2, P6 and P10 indicate treatments with $0,2,6$ or 10 weeks of polymer film coverage; P10+CAGE indicates the P10 treatment with addition of a wire cage to protect the polymer film from animal damage.

\begin{tabular}{|c|c|c|c|c|c|c|}
\hline Species & \multicolumn{6}{|c|}{ Treatment } \\
\hline & Control & PO & P2 & P6 & P10 & P10+CAGE \\
\hline Emergence (\%) & & & & & & \\
\hline Acacia dealbata & 47.3 & 43.2 & $32.5^{*}$ & $30.6^{*}$ & $35.4^{*}$ & $35.8^{*}$ \\
\hline Allocasuarina verticillata & 3.8 & $4.3^{*}$ & $1.2^{*}$ & $3.1^{*}$ & $2.1^{*}$ & $2.7^{*}$ \\
\hline Cassinia aculeata & 0.3 & 0.3 & 0.3 & 0.6 & 0.3 & $1.0^{*}$ \\
\hline Eucalyptus ovata & 6.3 & 6.9 & $4.1^{*}$ & $4.0^{*}$ & $7.8^{*}$ & 7.6* \\
\hline Hakea microcarpa & 1.3 & $0.6^{*}$ & $0.3^{*}$ & $0.2^{*}$ & $2.7^{*}$ & $6.8^{*}$ \\
\hline Persistence (\%) & & & & & & \\
\hline Acacia dealbata & 80.24 & 74.75 & 89.87 & 80.43 & 80.59 & 68.81 \\
\hline Allocasuarina verticillata & 45.04 & 41.70 & 47.92 & 45.81 & 36.71 & 42.15 \\
\hline Cassinia aculeata & 100.00 & 26.59 & 0 & 50.17 & 75.20 & 63.47 \\
\hline Eucalyptus ovata & 40.18 & 54.49 & 49.71 & 21.56 & 21.63 & 30.86 \\
\hline Hakea microcarpa & 13.63 & 0 & 0 & 0 & 14.28 & 0 \\
\hline
\end{tabular}





Figure 1. Impacts of clear polymer film (polymer film) on plant growing environment. (A) The polymer film creates a 'miniglasshouse', trapping soil and plant water and radiant heat. Rainfall runs off to each side of the polymer film, increasing soil water in its immediate vicinity. (B) The polymer film increases air and soil temperature, relative humidity and the $\mathrm{CO}_{2}$ concentration of the air, increases soil water content by reducing evaporation, and potentially increases soil microbial activity and nutrient availability. Radiation under the polymer film is reduced compared to ambient conditions. In theory these conditions can increase plant growth rate, but can also increase weed growth rates, and incidence of disease. 

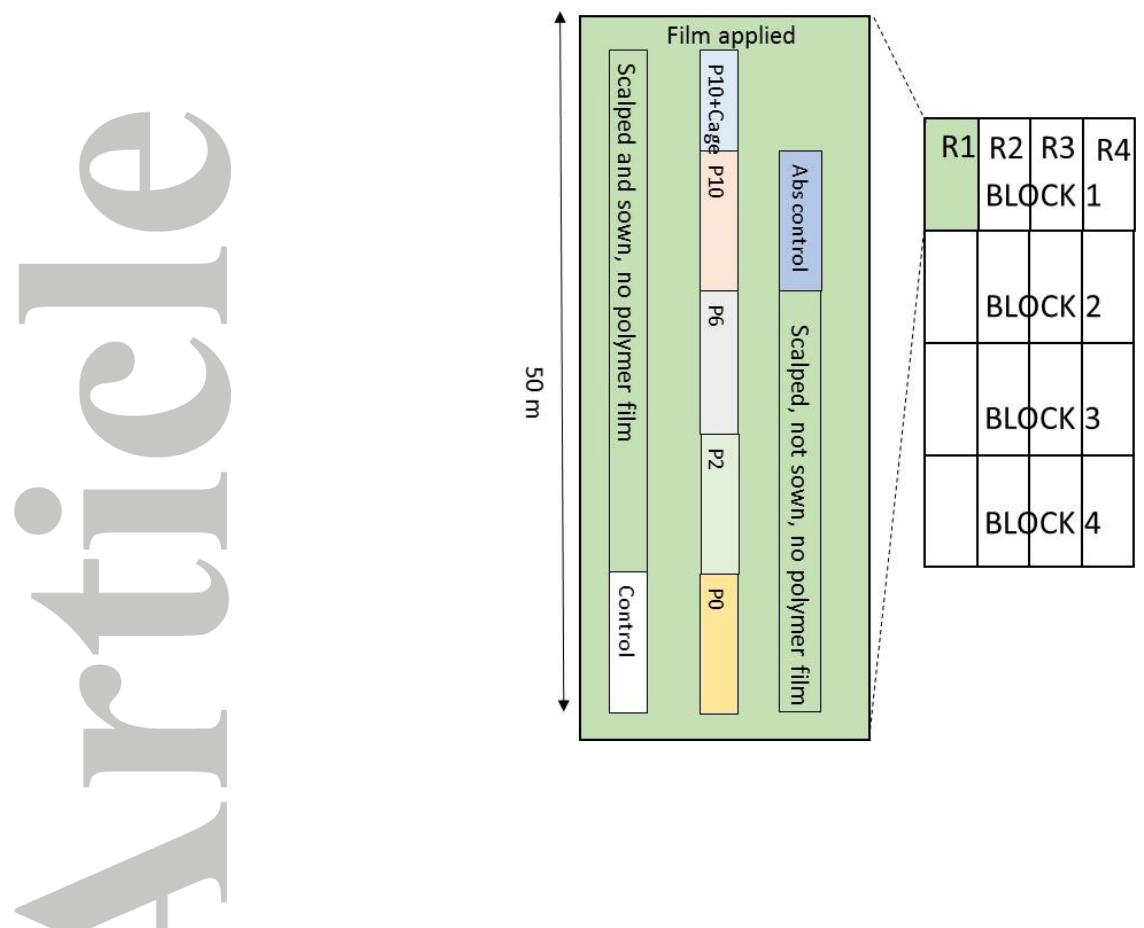

Figure 2. Representation of the layout of a single replicate. The experimental design consisted of four blocks of $50 \mathrm{~m}$ length, oriented down the slope, containing four replicates (R1-4) of each treatment within each block. This design gave a total of 16 replicates per treatment. Linear plots of $10 \mathrm{~m}$ length and the width of a sowing line (approx. $30 \mathrm{~cm}$ ) were established for each treatment replicate, with an internal measurement plot of $8 \mathrm{~m}$. For ease of application of polymer film, the plots with polymer film treatments were contiguous. Treatments 3 to 7 were randomly positioned within a $50 \mathrm{~m}$ sowing line, but the control plots (Treatment 1 and 2) were randomly placed on the adjacent sowing lines to which polymer film was not applied. Abs control=absolute control (scalped, no seed sown, no film); Control = seed sown, no film; $\mathrm{P0}=$ seed sown and film applied, film removed immediately; P2=film removed after 2 weeks; P6=film removed after 6 weeks; P10-film removed after 10 weeks; P10+cage=film +cage applied, film removed after 10 weeks. 

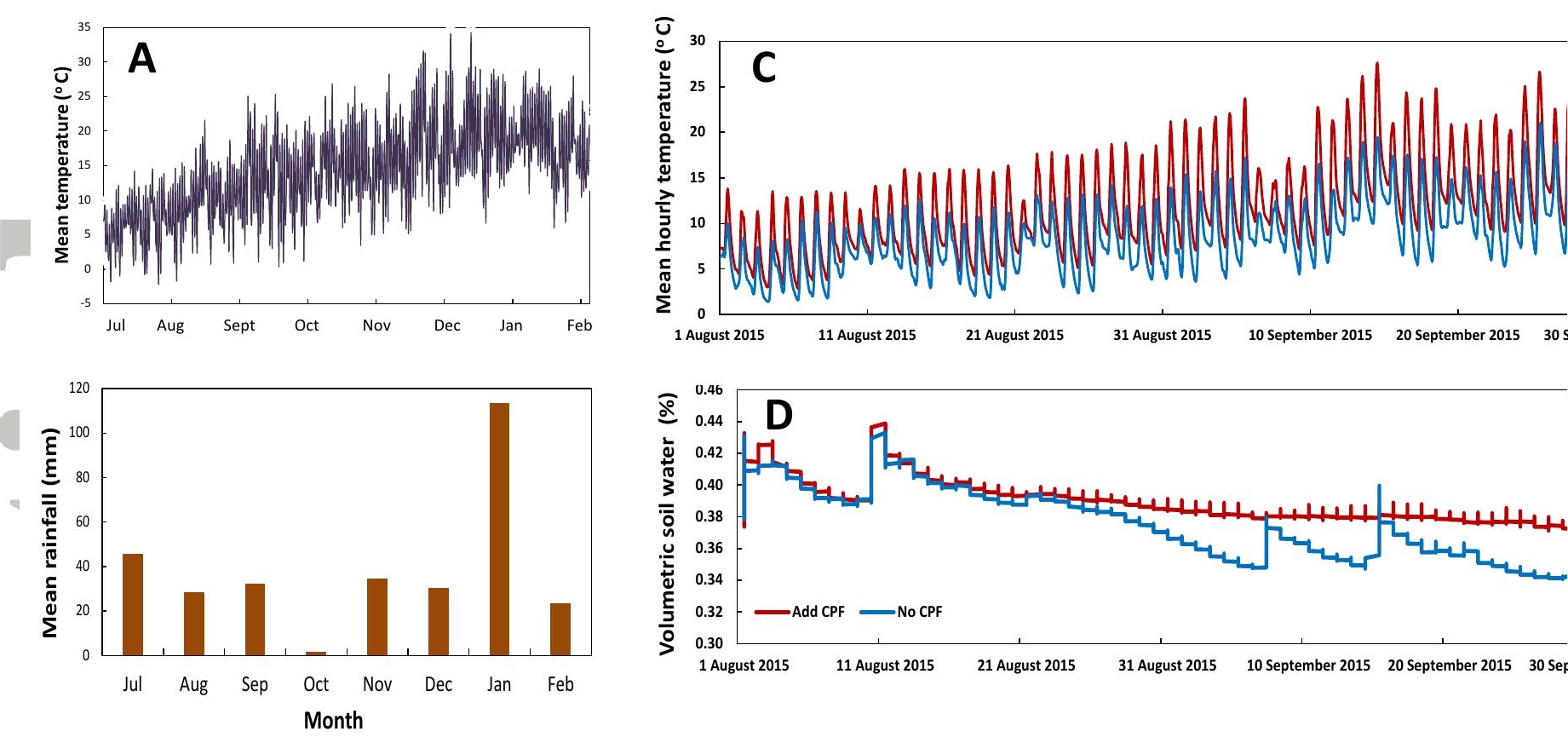

Figure 3. (A) mean hourly temperature measured at $1.3 \mathrm{~m}$ height over the duration of the experiment (July - February), and (B) mean monthly rainfall; (C) mean hourly temperature measured under polymer film and ambient conditions over the period that polymer film was present (July September), and (D) mean hourly volumetric soil water content, and relationship between (E) mean temperature and $(F)$ mean volumetric water content, measured at the soil surface with and without polymer film. The dotted line indicates the 1:1 relationship 

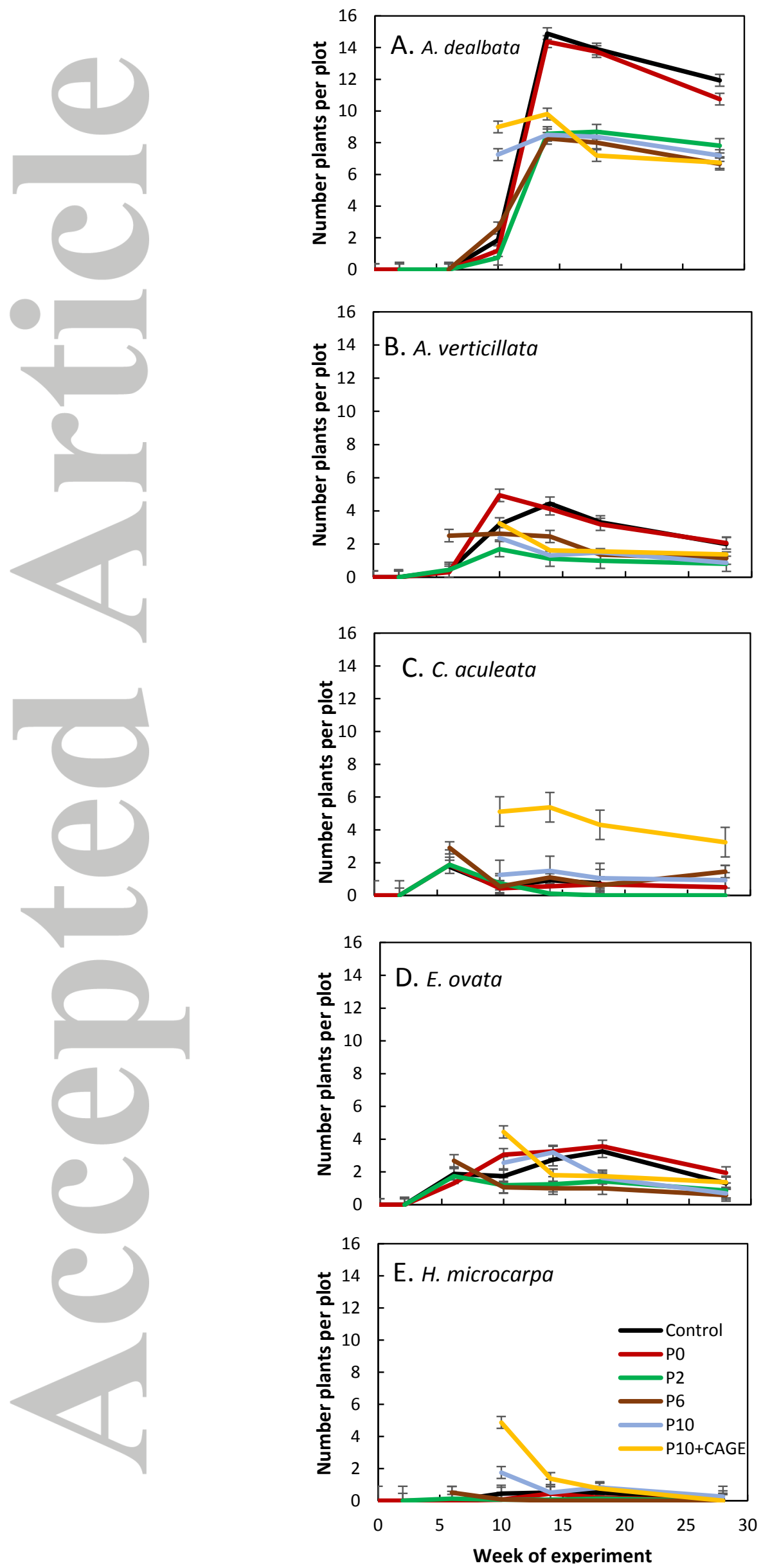

This article is protected by copyright. All rights reserved. 
Figure 4. Number of emergents of (A) Acacia dealbata; (B) Allocasuarina verticillata; (C) Cassinia aculeata, (D) Eucalyptus ovata and (E) Hakea microcarpa over the 28 weeks of the experiment. Error bars indicate standard errors calculated using least significant difference. Control had no polymer film coverage. P0, P2, P6 and P10 treatments had $0,2,6$ and 10 weeks of polymer film coverage respectively. P20+CAGE was the P10 treatment with wire caging to protect the polymer film from animal damage.

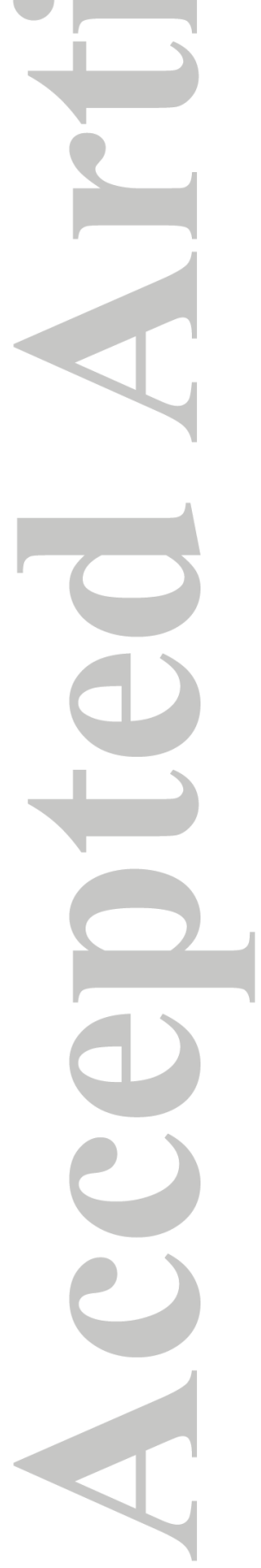

